\title{
APLICAÇÃO DE DIFERENTES FORMAS DE FERTILIZANTE ORGÂNICO NO SOLO PARA O RENDIMENTO DA CULTURA DO Zea mays
}

\author{
Gustavo Ferreira de Oliveira'; Diego Fernando Roters²; Marco Segalla Prazeres ${ }^{3}$. \\ 1Universidade do Estado de Santa Catarina (UDESC), Lages, Santa Catarina, gustavo_mania21@hotmail.com \\ 2 UDESC, Lages, Santa Catarina, diegoroters@gmail.com \\ 3 UDESC, Lages, Santa Catarina, marcosegalla@hotmail.com
}

RESUMO: A suinocultura brasileira passou a ser desenvolvida de maneira intensiva a partir da década de 1970 e vem tendo grande expansão em Santa Catarina, aumentando consideravelmente o número de animais por área. O estado possui aproximadamente nove milhões de cabeças, sendo o maior produtor nacional, responsável por 22\% da produção. O modelo de criação de suínos no estado gera expressivo volume de dejeto líquido de potencial poluidor de mananciais e contaminação do solo. Diante desse contexto o objetivo deste trabalho foi avaliar a eficiência do dejeto líquido suíno (DLS) como fertilizante para cultura do milho em diferentes formas de aplicaç̃̃es no solo, com e sem adição de NPK sob plantio direto. Este trabalho foi realizado durante a safra 2015/2016, em um experimento conduzido em um Cambissolo Húmico na região do Planalto Sul Catarinense, onde os tratamentos compreenderam as duas formas de aplicação: superficial (S) e incorporada (I); dois tipos de fertilizantes: o fertilizante mineral (NPK), o dejeto líquido suíno (DLS), e ausência de fertilização, compreendendo a parcela testemunha. O delineamento experimental utilizado foi blocos ao acaso, com quatro repetições. O rendimento de grãos foi influenciado pelos tratamentos, que aumentaram através da aplicação do fertilizante mineral ou do dejeto líquido suíno em comparação a ausência de fertilização, no entanto não houve diferença significativa entre os métodos aplicados.

PALAVRAS-CHAVE: Dejeto líquido suíno, Fertilização, Milho.

\section{APPLICATION OF DIFERENTE FORMS OF ORGANIC FERTILIZER IN THE SOIL FOR CROP YELD Zea mays}

\begin{abstract}
Brazilian pig farms began to be intensively developed in the 1970s and have been expanding in Santa Catarina, increasing considerably the number of animals per area, the state has approximately nine million head, being the largest national producer, responsible For $22 \%$ of production. The model of pig breeding in the state generates expressive volume of liquid waste from contaminant potential sources and contamination of the soil. In view of this context, the objective of this work was to evaluate the efficiency of the swine liquid waste (DLS) as fertilizer for maize cultivation in different forms of soil application, with and without NPK under no - tillage. This work was carried out during the
\end{abstract}


2015/2016 harvest, in an experiment conducted in a humic Cambisol in the region of Planalto Sul Catarinense, the treatments comprised the two forms of application: superficial (S) and incorporated (I); Two types of fertilizers: mineral fertilizer (NPK), swine net waste (DLS), and absence of fertilization, including the control plot. The experimental design was a randomized block design, with four replications. The grain yield was influenced by the treatments, which increased through the application of the mineral fertilizer or swine net waste in comparison to the absence of fertilization, however there was no significant difference between the applied methods.

KEYWORDS: Corn, Fertilization, Swine.

\section{APLICACIÓN DE DIFERENTES FORMAS DE FERTILIZANTE ORGÁNICO EN EL SUELO PARA LA RENDIMIENTO DE LA CULTURA DEL Zea mays}

RESUMEN: La suinocultura brasileña pasó a ser desarrollada de manera intensiva a partir de la década de 1970 y viene teniendo gran expansión en Santa Catarina, aumentando considerablemente el número de animales por área. El estado posee aproximadamente nueve millones de cabezas, siendo el mayor productor nacional, responsable del 22\% de la producción. El modelo de cría de cerdos en el estado genera expresivo volumen de desechos líquidos de potencial contaminante de manantiales y contaminación del suelo. Ante este contexto el objetivo de este trabajo fue evaluar la eficiencia del desecho líquido porcino (DLS) como fertilizante para cultivo del maíz en diferentes formas de aplicaciones en el suelo, con y sin adición de NPK bajo plantación directa. Este trabajo fue realizado durante la cosecha 2015/2016, en un experimento conducido en un Cambiolo húmico en la región del Planalto Sur Catarinense, donde los tratamientos comprendieron las dos formas de aplicación: superficial (S) e incorporada (I); Dos tipos de fertilizantes: el fertilizante mineral (NPK), el desecho líquido porcino (DLS), y la ausencia de fertilización, incluyendo la porción testigo. El delineamiento experimental utilizado fue bloques al azar, con cuatro repeticiones. El rendimiento de granos fue influenciado por los tratamientos, que aumentaron a través de la aplicación del fertilizante mineral o del desecho líquido porcino en comparación con la ausencia de fertilización, sin embargo no hubo diferencia significativa entre los métodos aplicados.

PALABRAS CLAVE: Desecho líquido porcino, Fertilización, Maíz.

INTRODUÇÃO

○ setor suinícola detém grande

importância econômica e social no cenário agrícola brasileiro. Este setor agropecuário se destaca no sul do Brasil com concentração de $44 \%$ do rebanho 
nacional e 61\% do alojamento tecnificado de matrizes. A produtividade da suinocultura brasileira é variável, dependendo da região e do tipo de produção, alcançando, um desfrute de 170\% no estado de Santa Catarina, comparável ao obtido por alguns dos países produtores com maiores índices produtivos (EMBRAPA, 2006).

A suinocultura brasileira passou a ser desenvolvida de maneira intensiva a partir da década de 1970 (BORDIM, 2005; CERRI et al., 2010; BRASIL, 2011) e vem tendo grande expansão em Santa Catarina, aumentando consideravelmente o número de animais por área. $\mathrm{O}$ estado possui aproximadamente nove milhões de cabeças, sendo o maior produtor nacional, responsável por 22\% da produção (ABIPECS, 2011) e por 34\% das exportações de carne suína (ACCS, 2013).

A suinocultura é uma atividade que se caracteriza pelo sistema intensivo de produção, gerando grande volume de dejetos liquido suíno (DLS), esse produto provoca poluição ambiental, principalmente em locais declivosos e com pequena área agrícola disponível para sua aplicação (OLIVEIRA, 2017).

O DLS é um resíduo oriundo da atividade suinícola, que tem grande potencial poluidor, quando manejado de maneira indiscriminada, como sua aplicação em locais declivosos e próximos a cursos d'água. Para o uso mais eficiente deste resíduo, estudos foram realizados com o intuito de melhor aproveitar seu potencial agronômico como fonte de nutrientes às culturas (SCHERER et al., 2010; SANTOS, 2016; SANTOS et al., 2016). A partir desta premissa uma atenção passou a ser dada na reciclagem destes resíduos, com o objetivo de reduzir o impacto sobre o ambiente através da capacidade de ciclagem que o solo possui (BARILI, 2005).

grande número de animais criados em confinamento produz diariamente um volume considerável de dejetos, gerando passivo ambiental que requer soluções adequadas. $\bigcirc$ dejeto é composto pelos resíduos de fezes e urina dos animais, restos de ração e pela água dos bebedouros e da higienização das 
baias que resultam em resíduo na forma líquida. O (DLS) pode ser usado como fertilizante por conter nutrientes essenciais as plantas (CASSOL et al., 2012).

Aumentos na produtividade do milho fertilizado com DLS foram constatados por diversos autores (CERETA et al. 2005a; GIACOMINI; AITA, 2008; LÉls et al., 2009; CASSOL et al., 2012). Porém o manejo empregado pelos produtores com aplicações superficiais e sucessivas geralmente resultam em altas doses de nitrogênio e elevadas taxas de nitrificação (AITA et al., 2007), contaminação dos lençóis freáticos por lixiviação do nitrato. Por outro lado, essa fertilização superficial aumenta os riscos de perdas por escoamento superficial do resíduo que pode vir a poluir mananciais, causando eutrofização das águas e ainda contaminação por coliformes fecais (BASSO, 2005).

Diante desse contexto o objetivo deste trabalho foi avaliar a eficiência do dejeto líquido suíno (DLS) como fertilizante para cultura do milho em diferentes formas de aplicações no solo, com e sem adição de NPK sob plantio direto.

\section{MATERIAL E MÉTODOS}

O experimento foi conduzido na safra 2015/2016 na área experimental da Universidade do Estado de Santa Catarina, Centro de Ciências Agroveterinárias (UDESC/CAV), no município de Lages.

O solo é um Cambissolo Húmico Alumínico, de textura argilosa (EMBRAPA, 2004), manejado sob semeadura direta desde o ano de 2011. Os tratamentos constituíram um fatorial de $2 \times 3$, sendo dois métodos de aplicação, superficial e incorporado, combinado com três fertilizações, compostas de controle, sem fertilizante; fertilizante mineral (NPK); e DLS, compreendeu nas doses de 130, 185 e $70 \mathrm{~kg} / \mathrm{ha}^{-1}$ de $\mathrm{N}, \mathrm{P}_{2} \mathrm{O}_{5}$ e $\mathrm{K}_{2} \mathrm{O}$, respectivamente e o DLS a dose 40 $\mathrm{m}^{3} / \mathrm{ha}^{-1}$, fixada para fornecer $120 \mathrm{Kg} / \mathrm{ha}^{-1}$ de $N$ total, com uma densidade de plantas de 117.000 de milho. 0 delineamento experimental utilizado foi blocos casualizado, com quatro repetições de parcelas com área de 40 
$m^{2}(8 m \times 5 m)$. As doses de nutrientes foram definidas visando o rendimento de 8,0 Mg/ha-1, conforme recomendação da CQFS RS/SC (2004).

O DLS foi obtido a partir de uma granja de produção de leitões, sendo que foi utilizado, 1/2 dos dejetos oriundos de um biodigestor e $1 / 2$ oriundo de uma lagoa que recebe o efluente proveniente do biodigestor. As concentrações de nutrientes do DLS, conforme metodologia descrita por Tedesco et al. (1995) são demonstradas na (Tabela 1).

Tabela 1. Teores de massa seca, $\mathrm{N}$ total, $\mathrm{N}$ amoniacal e $\mathrm{P}$ total em dejeto líquido de suíno gerado em granja de produção de leitões no município de Campos Novos.

\begin{tabular}{cccc}
\hline Massa seca & $\mathrm{N}$ & $\mathrm{P}$ & $\mathrm{N}-\mathrm{NH}_{4}$ \\
\hline- & & $\mathrm{N}^{--}$ & \\
54,9 & 3,0 & 3,5 & 1,8 \\
\hline
\end{tabular}

A injeção do DLS no solo foi realizada por um equipamento desenvolvido pela empresa MEPEL, composto de um tanque metálico com capacidade para 4.000 L, com bomba para sucção e aplicação de dejetos líquidos, acionada pela tomada de potência do trator. Na parte traseira, o equipamento contém um conjunto de linhas de injeção distanciadas em 35 cm, as quais são fixadas no chassi do equipamento. O conjunto é acionado por meio de pistão hidráulico central conectado por mangas de alta pressão ao sistema hidráulico do trator. A profundidade de injeção dos dejetos pelo equipamento é de aproximadamente $8 \mathrm{~cm}$ de profundidade e a faixa de solo mobilizado na superfície do sulco de 10 a $12 \mathrm{~cm}$.

Nos tratamentos com aplicação dos dejetos na superfície do solo, a distribuição foi feita manualmente, com auxílio de regadores, com capacidade de 10 L. Já os tratamentos com NPK foram aplicados manualmente, a lanço quando em superfície e em linha quando injetado, sendo neste caso distribuídos dentro do sulco aberto pelo mesmo 
equipamento utilizado na injeção do DLS.

Foi cultivado milho (Zea mays) em sistema plantio direto empregando-se a cultivar 30F53 (Pioneer ${ }^{\circledR}$ ), de elevado potencial produtivo. Após a colheita, avaliou-se a produtividade mediante amostragem de 20 plantas por parcela na fase de maturação fisiológica, através das seguintes variáveis (componentes de rendimento): i) Comprimento de espiga (CEsp): através da distância entre o primeiro e o último grão da linha mais longa, medida com um paquímetro manual; ii) Número de grãos por espiga (NGEsp): foi determinado pela equação (2), a determinação de umidade foi recomendado segundo Tedesco (1995); iii) Rendimento de grãos: através da densidade populacional por hectare.

Os resultados obtidos foram submetidos a comparação de médias pelo teste Tukey a 5\% de significância $(P<0,05)$.

\section{RESULTADOS E DISCUSSÃO}

A fertilização aumentou o rendimento de milho em relação ao controle, independentemente da fonte ter sido orgânica (DLS) ou mineral (NPK) em comparação a ausência de fertilização. O rendimento de grãos da cultura do milho variou de 4,0 a 8,8 $\mathrm{Mg} / \mathrm{ha}^{-1}$ (Tabela

2).

Tabela 2. Rendimento de grãos e demais parâmetros produtivos da cultura do milho.

\begin{tabular}{ccccc}
\hline $\begin{array}{c}\text { Modo de } \\
\text { Aplicação }\end{array}$ & $\begin{array}{c}\text { Fertilizante } \\
\text { mineral }\end{array}$ & $\begin{array}{c}\text { Dejeto } \\
\text { Líquido Suíno }\end{array}$ & Controle & Média \\
\hline \multicolumn{4}{c}{ Rendimento de Grãos Mg/ha ${ }^{-1}$} \\
Incorporado & $7,4 \mathrm{a}$ & $7,8 \mathrm{a}$ & $4,0 \mathrm{~b}$ & $6.4 \mathrm{~A}$ \\
Superficial & $8,8 \mathrm{a}$ & $8,4 \mathrm{a}$ & $4,4 \mathrm{~b}$ & $7.2 \mathrm{~A}$ \\
Incorporado & $193,00 \mathrm{a}$ & $206,65 \mathrm{a}$ & $116,95 \mathrm{~b}$ & $172,2 \mathrm{~A}$ \\
Superficial & $238,25 \mathrm{a}$ & $195,60 \mathrm{a}$ & $128,35 \mathrm{~b}$ & $187,4 \mathrm{~A}$ \\
Incorporado & $7,6 \mathrm{a}$ & $7,8 \mathrm{a}$ & $6,7 \mathrm{~b}$ & $7,4 \mathrm{~A}$ \\
Superficial & $8,5 \mathrm{a}$ & $8,3 \mathrm{a}$ & $6,2 \mathrm{~b}$ & $7,7 \mathrm{~A}$ \\
\hline
\end{tabular}


O resultado indicou que para o nível de produtividade encontrado no experimento, o DLS e NPK forneceram quantidades semelhantes de nutrientes. Os valores de grãos por espiga variaram de 116,95 a 238,25 por unidade, apresentando diferença significativa entre NPK e DLS em relação ao controle. Entretanto, os resultados não diferiram entre as formas de aplicação dos fertilizantes (NPK e DLS).

O comprimento de espiga variou de 6,2 a 8,5 (cm), havendo diferença significativa entre os tratamentos NPK e DLS em relação ao controle e não apresentaram diferença entre as parcelas fertilizadas (NPK e DLS).

Observa-se que dentre os valores encontrados, o tratamento com aplicação S1P3, foi o que apresentou o maior rendimento de grãos, onde foi aplicado O DLS puro superficialmente, demonstrando que o DLS supriu as exigências nutricionais para a cultura do Milho de alta densidade de plantio, tanto quanto o fertilizante mineral.

No trabalho de Giacomini et al. (2009) e Alves et al. (2012) e os autores evidenciaram que as fontes de fertilizantes orgânico e mineral, não diferiram entre si no rendimento de grãos, o que demonstra que o DLS supriu as exigências nutricionais para a cultura do milho tanto quanto o fertilizante mineral resultados que corroboram os encontrados neste trabalho.

Segundo Alves et al. (2016) que avaliaram os parâmetros produtivos do milho em solo fertilizados com dejeto suíno aplicado superficialmente ou incorporado, observaram que o número de espigas por $\mathrm{m}^{2}$ foi relativamente alto na forma de aplicação incorporada, refletindo na a alta densidade de plantas obtida na lavoura.

Segundo os mesmos autores isso acarretou redução na massa de grãos por espigas, que foi maior nos tratamentos fertilizados em relação ao controle, não fertilizado. O número de grãos por espiga, também foi afetado pela densidade e aumentou com a fertilização, tanto com a fonte orgânica quanto com o mineral, isso mostra que o DLS manejado de forma 
agronomicamente sustentável e seguindo as recomendações adequadas para sua aplicação no solo é uma alternativa viável como fertilizante para cultura do milho.

As duas fontes de nutrientes testadas, mineral e DLS, demonstraram aparente superioridade no rendimento de grãos, quando comparado ao controle, onde não houve adubação, havendo maiores valores na aplicação DLS em relação a testemunha e aplicação de NPK, porém estatisticamente não ocorreram diferenças significativas, ocorrendo rendimento de grãos de milho em até $8,4 \mathrm{Mg} / \mathrm{ha}^{-1}$. O dejeto líquido de suíno apresentou eficiência equivalente ao fertilizante mineral, sendo valor superior nas áreas de aplicação de sulcos, porém sem diferença estatística.

\section{CONCLUSÃO}

As duas fontes de nutrientes testadas, mineral e DLS, demonstraram aparente superioridade no rendimento de grãos, quando comparado ao controle, onde não houve adubação, havendo maiores valores na aplicação DLS em relação a testemunha e aplicação de NPK.

O dejeto líquido de suíno apresentou eficiência equivalente ao fertilizante mineral, sendo valor superior nas áreas de aplicação de sulcos, porém sem diferença estatística.

Tais variáveis indicam que através da reciclagem destes dejetos podemos de forma sustentável substituir o fertilizante mineral sem afetar o rendimento de grãos e incrementar os lucros da propriedade, sendo a forma de manejo empregado na aplicação DLS, podendo apresentar um incremento no rendimento que em relação a aplicação em superfície.

\section{REFERÊNCIAS}

AITA, C.; GIACOMINI, S. J.; HUBNER, A. P. Nitrificação do nitrogênio amoniacal de dejetos líquidos de suínos em solo sob sistema de plantio direto. Pesquisa Agropecuária Brasileira, v. 42, p. 95-102, 2007.

ALVES, C. T. F.; CASSOL, P. C.; GATIBONE, L. C.; MAFRA, A. L.; RAUBER, L. P.; MAFRA, M. S. H.; FERREIRA, A. K.; GRÓHSKOPF, M. A.; MINATTI, M. Produtividade do Milho em Solo Fertilizado com Dejetos Suíno em 
Aplicação Incorporada e na Superfície. In: FertBio:

A responsabilidade socioambiental da pesquisa agrícola. Maceió, Alagoas, 2012.

ALVES, C. T. F.; ORSOLETTA, D. J.; SACOMORI, W.; RAUBER, L. P.; CASSOL, P. C.; GATIBONE, L. C.; MAFRA, A. L.; BRANDT, A. A.; PANISSON, J. Parâmetros produtivos do milho em solo fertilizados com dejeto suíno aplicado superficialmente ou incorporado. In: II SIMPÓSIO INTERNACIONAL DE INOVAÇÃO DE CADEIA PRODUTIVA DO AGRONEGÓCIO. Anais... Caxias do Sul, RS, 2016.

ASSOCIAÇÃO CATARINENSE DE CRIADORES DE SUÍNO - ACCS, 2013. Disponível em < http://www.accs.org.br/ >. Acesso em 27 de Maio de 2013.

ASSOCIACAO BRASILEIRA DA
INDUSTRIA PRODUTORA E EXPORTADORA DE CARNE SUINA ABIPECS, 2009. Disponível em: <http://www.abipecs.org.br>. Acesso em: 27 mai. 2013.

\section{BARILLI, J. Atributos de um Latossolo} Vermelho sob aplicação de resíduos de suínos. 2005. 77 p. Tese (Doutorado). Faculdade de Ciências Agronômicas, Universidade Estadual Paulista, Botucatu.

BASSO, J. C.; CERETTA, C. A.; DURIGON, R.; POLETTO, N.; GIROTTO, E. Dejeto Líquido de Suíno: Perdas de Nitrogênio e Fósforo por percolação no solo sob plantio direto. Ciência Rural, Santa Maria, v. 35, n. 6, p. 1305-1312, nov-dez, 2005.
BRASIL. Projeções do agronegócio 2010/2011 a 2020/2021. Brasília: MAPA, 2011. Disponível em: http://www.agricultura.gov.br/arq_editor/ file/Ministerio/gestao/projecao/PROJECO ES\%20DO\%20AGRONEGOCIO\%20201011\%20a\%202020-21\%20-\%202_0.pdf>. Acesso em: 10 jan. 2017.

BORDIM, R. A.; PEREIRA, C. A. D.; EBOLI, M.; ARTILHEIRO, R.; FREITAS, C. A produção de dejetos e o impacto ambiental da suinocultura. Revista de Ciências Veterinárias. Anhanguera, v. 3, n 5, p 1-4, 2005.

CASSOL, P. C.; COSTA, A. C.; CIPRANDI, O.; PANDOLFO, C. M.; ERNANI, P. R. Disponibilidade de macronutrientes e rendimento de milho em Latossolo fertilizado com dejeto. Revista brasileira de ciências do solo, v.36, n.6 2012. Disponível em: http://www.scielo.br/pdf/rbcs/v36n6/25.p df >. Acesso em: 01 mar. 2013.

CERETTA, C. A.; BASSO, C. J.; VIEIRA, F. C. B.; HERBES, M. G.; MOREIRA, I. C. L.; BERWANGER, A. L. Dejeto líquido de suínos: I-Perdas de nitrogênio e fósforo na solução escoada na superfície do solo, sob plantio direto. Ciência Rural, v. 35, n. 6, p. 1296-1304, 2005b.

CERRI, C. C.; BERNOUX, M.; MAIA, S. M. F.; CERRI, C. E. P.; COSTA JÚNIOR, C.; FEIGL, B. J.; FRAZÃO, L. A.; MELLO, F. F. C.; GALDOS, M. V.; MOREIRA, C. S.; CARVALHO, J. L. N. Greenhouse gas mitigations in Brazil for land-use change, livestock and agriculture. Scientia Agricola, v. 67, n. 1, 2010. 
COMISSÃO DE QUÍMICA E FERTILIDADE DO SOLO - RS/SC - CQFS - RS/SC. Manual de adubação e de calagem para os estados do Rio Grande do Sul e Santa Catarina. 10. ed. Porto Alegre: SBCSNúcleo Regional Sul, 2004. 400p.

EMBRAPA - EMPRESA BRASILEIRA DE PESQUISA AGROPECUÁRIA. Centro Nacional de Pesquisa de Solos. Sistema Brasileiro de Classificação de solos. 2.ed. Rio de Janeiro, 2006. 306p.

GIACOMINI, S. J.; AITA, C. Cama sobreposta e dejetos líquidos de suínos como fonte de nitrogênio ao milho. Revista Brasileira de Ciência do Solo, v. 32, n. 1, p. 195-205, 2008.

GIACOMINI, S. J.; AITA, C.; JANTALIA, C. P.; URQUIAGA, S. Aproveitamento pelo milho do nitrogênio amoniacal de dejetos líquidos de suínos em plantio direto e preparo reduzido do solo. Pesquisa Agropecuária Brasileira. v.44, p.761-768, 2009.

LÉIS, C. A.; COUTO, R. R.; DORTZ BACH, D.; COMIN, J. J.; SARTO, L. R. Rendimento de milho adubado com dejetos de suínos em sistema de plantio direto sem o uso de agrotóxicos. Revista Brasileira de Agroecologia, v. 4, n. 2, p. 3814-3817, 2009.

OLIVEIRA, G. F. Volatilização de a mônia em solo em diferentes umidades, coberto com palha, após a incorporação de dejeto líquido suíno. 76 p. Dissertação (Mestrado). Programa de Pós-graduação em Ciência do Solo, Universidade do Estado Santa Catarina, Lages, Santa Catarina, 2017.
SANTOS, D. B. Acúmulo de carbono no solo e potencial de aquecimento global influenciado pelo modo de aplicação de dejetos líquidos de suínos e inibidor de nitrificação. 80f. Tese (Doutorado em Ciência do Solo) - Universidade Federal de Santa Maria, Santa Maria, 2016.

SANTOS, S. M. C.; ANTONANGELO, J. A.; DEUS, A. C. F.; FERNANDES, D. M. Perdas de amônia por volatilização em resposta a adubação nitrogenada do feijoeiro. Revista de Agricultura Neotropical. v.3 n.1, p 16-20p, 2016.

TEDESCO, M. J.; GIANELLO, C.; BISSANI, C. A.; BOHNEN, H.; VOLKWEISS, S. J. Análises de solo, plantas e outros materiais. Porto Alegre: Universidade Federal do Rio Grande do Sul, 1995. 174p. (Boletim Técnico,5). 